Revista Energia na Agricultura

ISSN 1808-8759

\title{
EVOLUÇÃO DA ÁREA FLORESTADA NA REGIÃO DE BOTUCATU - SP NO PERÍODO DE 1996 A 2008 VISANDO À IMPLANTAÇÃO DA RESERVA LEGAL PEDRO FERNANDO CATANEO ${ }^{1} \&$ OSMAR DE CARVALHO BUENO $^{2}$
}

RESUMO: Devido às atuais discussões sobre a Reserva Legal, este trabalho tem por objetivo conhecer a distribuição das áreas agrícolas da região de Botucatu, em suas variadas explorações, com especial ênfase às áreas de mata natural, comparar os valores municipais com aqueles dispostos no Código Florestal Brasileiro, de forma a analisar o processo de implantação dos $20 \%$ de área de florestas em relação à área total agrícola, em nível macro municipal e regional, sem considerar as áreas de cada uma das propriedades agrícolas e nem a bacia hidrográfica às quais pertencem, conforme consta no Código Florestal Brasileiro. Os resultados do trabalho mostram que todos os municípios pertencentes à região não possuem áreas de mata natural superiores a $20 \%$ e que terão que reflorestar sem finalidade exploratória, a não ser cumprir os preceitos da legislação. Para a implantação de florestas para compor o percentual de 20\% de Reserva Legal, em nível macro, até o ano de 2021, quando termina o prazo disposto no Código Legal, Bofete, Botucatu, Itatinga e Pardinho encontrarão as menores dificuldades, Anhembi, Conchas, Laranjal Paulista, Pereiras, Pratânia e São Manuel terão dificuldades médias, enquanto que Areiópolis encontrará a maior dificuldade.

Palavras-chave: Índices de Reflorestamento, Reflorestamento, Código Florestal.

\footnotetext{
${ }^{1}$ Professor Universitário, Faculdade Iteana de Botucatu, Av. Alcides Cagliari, 2601, Botucatu, SP, CEP 18606-855, pedcataneo@gmail.com

${ }^{2}$ Professor Universitário, Faculdade de Ciências Agronômicas de Botucatu, Fazenda Lageado, Botucatu, SP, CEP 18600-000,osmar@fca.unesp.br
} 


\section{ENLARGEMENT OF THE FORESTED AREA IN THE REGION OF BOTUCATU, BRAZIL, FROM 1996 TO 2008, AIMING AT THE IMPLEMENTATION OF A LEGAL FOREST RE- SERVE}

SUMMARY: Due to the considerations on the Legal Forest Reserve, the aim of this paper is to show the distribution of the farming areas in the region and their application - especially natural forests. Also, to compare the municipal values with those stated in the Brazilian Forest Code in order to analyze the process of implementing $20 \%$ of forest area in relation to the total farming area, at municipal and regional levels, not considering the areas of each of the farms nor the watershed to which they belong with the Brazilian Forestry Code. The work results show that all municipalities in the region of Botucatu do not have forest areas equal or greater than 20\% of total area. Therefore, a non-exploratory reforestation procedure will have to be implemented to follow legal requirements. Finally, the results show that the city of Areiópolis will face the greatest difficulties in implementing the $20 \%$ of forests with regard to the Legal Forest Reserve, until 2021, when the deadline stated by the Legal Code expires. According to the same variables, the municipalities of Anhembi, Conchas, Laranjal Paulista, Pereiras, Pratânia and São Manuel will face medium-level difficulties, whereas Bofete, Botucatu, Itatinga and Pardinho will implement it the easiest way.

Keywords: Reforestation Indexes, reforestation, Brazilian forestry code.

\section{INTRODUÇÃO}

A Constituição Federal, a partir da criação de espaços territoriais especialmente protegidos, permite o estudo dos instrumentos de proteção ambiental que delimitam a função ambiental da propriedade rural, cabendo ao Poder Público, conforme diz o art. 255 da Constituição Federal, definir espaços territoriais e seus componentes a serem protegidos, em todas as Unidades da Federação, sendo toda supressão possível somente através de lei e vedada qualquer utilização que comprometa os atributos que justifiquem sua proteção.

A Constituição Federal, em conjunto com outras normas que tratam especificamente da função ambiental da propriedade, fundamentam toda a legislação sobre os espaços públicos e privados que devem ser submetidos a regimes especiais de proteção. Alguns exemplos dessas normas são o Código Florestal (Lei $n^{\circ}$. 4.717/65), a Lei $n^{\circ}$. 6.902/81, o Decreto $n^{\circ}$. 99.274/90 e a Lei 9.985, de 18 de julho de 2000, que 
regulamentam áreas de reserva legal, áreas de preservação permanente, parques, reservas biológicas, estações ecológicas, áreas de proteção ambiental, florestas públicas e particulares, o patrimônio nacional e outros espaços especiais. Como essa legislação encontra-se dispersa, sempre ocorrem dificuldades na identificação de um espaço territorial específico e seu regime.

A Reserva Legal, pelos arts. 16 e 44 do Código Florestal, é constituída por áreas de cobertura arbóreas localizada, a critério da autoridade competente, delimitadas territorialmente em propriedades, sejam privadas ou públicas, onde não é permitido o corte raso. O percentual de reserva legal difere de acordo com a região do país onde o imóvel estiver situado, bem como pelo tipo de cobertura florestal indicada, sendo no mínimo de 80\% da propriedade rural em área de floresta localizada na Amazônia Legal, 35\% em área de cerrado localizada na Amazônia Legal, no mínimo 20\% na forma de compensação em outra área, desde que esteja localizada na mesma microbacia, e seja averbada; 20\% em área de floresta ou outras formas de vegetação nativa localizada nas demais regiões do País e 20\% em área de campos gerais localizada em qualquer região do País. As duas últimas possibilidades ainda incluem a averbação "à margem da inscrição de matrícula do imóvel, no registro de imóveis competente, sendo vedada a alteração de sua destinação nos casos de transmissão, a qualquer título, ou de desmembramento da área”. Se aplica o disposto no Código Florestal a todas as propriedades, posto que a lei fale em 20\%, no mínimo, de cada propriedade, porém, historicamente, isso nunca foi observado pela grande maioria dos proprietários rurais.

Devido às atuais discussões sobre a formação da Reserva Legal, este trabalho teve por objetivo conhecer a distribuição das áreas agrícolas da Regional de Botucatu em suas variadas explorações, com especial ênfase às áreas de mata natural, comparar os valores municipais com aqueles dispostos no Código Florestal Brasileiro, de forma a analisar o processo de implantação dos $20 \%$ de área de florestas em relação à área total agrícola, em nível macro municipal e regional, sem considerar as áreas de cada uma das propriedades agrícolas e nem a bacia hidrográfica às quais pertencem.

\section{MATERIAL E MÉTODOS}

Utilizaram-se dados secundários de levantamentos efetuados pela CATI - Coordenadoria de Assistência Técnica Integral, órgão ligado à Secretaria de Agricultura do Estado de São Paulo, por meio do Projeto LUPA - Levantamento das Unidades de Produção Agropecuária, nas propriedades rurais do estado de São Paulo nos anos de 1995/1996 (SÃO PAULO, 1997) e em 2007/2008 (SÃO PAULO, 2009). 
Uma UPA é definida como o conjunto de propriedades agrícolas contíguas e pertencentes aos mesmos proprietários; localizadas inteiramente dentro de um mesmo município, inclusive dentro do perímetro urbano; com área total igual ou superior a 0,1ha não destinada exclusivamente para lazer. Em princípio, uma UPA é exatamente o mesmo que um imóvel rural, excetuando-se os casos onde o imóvel rural se estende por mais de um município, quando se considera cada uma das partes em municípios diferentes como uma UPA e quando não é possível levantar o imóvel rural como tal, sendo necessário reparti-lo ou agrupá-lo com outros.

OLUPA abrange as explorações vegetais e animais, mas não as atividades de extrativismo. Os dados levantados situam-se na classe de ocupação do solo: área com cultura perene, área com cultura temporária, área com pastagem, área com reflorestamento, área de vegetação natural, área em descanso, área de vegetação de brejo e várzea e área complementar. A área da UPA é igual à soma dessas áreas. A área de vegetação natural compreende as terras ocupadas com diversos tipos de vegetação natural, incluindo mata natural, capoeira, cerrado, cerradão, campos e similares. A mata natural refere-se a toda área de vegetação ainda intocada pelo ser humano, bem como aquelas em adiantado grau de regeneração. A capoeira refere-se à fase inicial de regeneração de uma mata natural. Cerrado/cerradão refere-se a esse tipo próprio de vegetação e suas variações, como campo limpo e campo sujo.

Esses dados e suas evoluções entre 1995/1996 e 2007/2008 permitem inferir sobre a necessidade de disponibilizar áreas para regeneração da vegetação natural em cada um dos municípios, em nível macro, ou seja, para o conjunto de todas as suas propriedades rurais, e não por propriedade ou bacia hidrográfica, como recomendado pelo Código Florestal Brasileiro. Essa é a única forma possível pelo nível de agregação das informações publicadas pela Secretaria da Agricultura. O mesmo cálculo foi efetuado para o total da região de Botucatu. Os dados obtidos permitiram desenvolver análise econômica e tecer comentários sobre os impactos econômicos dessa medida em cada um dos municípios.

Os dados permitiram desenvolver cálculos do Índice de Gini, de acordo com Hoffmann (1998) que apresenta várias formulações, com suas diversas aplicações. Na aplicação clássica, o índice de Gini mede o grau de desigualdade existente na distribuição de indivíduos segundo a renda domiciliar per capita. Pela expressão utilizada neste trabalho seu valor variou de 0 , quando não havia desigualdade (a renda de todos os indivíduos tem o mesmo valor), isto é, a concentração é nula, até 1, quando a desigualdade é máxima (apenas um indivíduo detém toda a renda da sociedade e a renda de todos os outros indivíduos é nula), ou seja, a concentração é absoluta.

Adaptando-se para as variáveis existentes neste trabalho, o índice de Gini foi calculado pela seguinte expressão:

$$
G=\left|1-\sum_{k=1}^{n-1}\left(X_{k+1}-X_{k}\right)\left(Y_{k+1}+Y_{k}\right)\right|
$$


onde $\mathrm{X}_{\mathrm{k}}$ e $\mathrm{Y}_{\mathrm{k}}$ são, respectivamente, as porcentagens acumuladas do número de imóveis rurais e da área ocupada até o estrato k, sendo n o número total de estratos. Outras formulações do índice de Gini são encontradas em Hoffmann (1980), Hoffmann (2001) e Olivette e Camargo (2009). O Índice de Gini foi utilizado com a finalidade de aferir a desigualdade existente na distribuição de área agrícola entre os proprietários. Para isso trabalhou-se com duas distribuições: a de freqüências de proprietários e a de área das propriedades, em ha.

Também foram utilizados dados de todos os municípios, produzidos pela Target do Brasil, em 2008 (TARGET DO BRASIL, 2008). Esses dados referem-se à população rural dos municípios e consumo per capita na zona rural.

As variáveis que compõem este estudo são aquelas originais dos levantamentos efetuados pela Secretaria de Agricultura do Estado de São Paulo em 1995/1996 e em 2007/2008, da Target do Brasil, para o ano de 2008, assim como aquelas calculadas por meio das originais, para todo o estado, por regional agrícola e por município componente da Regional de Botucatu da Secretaria da Agricultura do Estado de São Paulo.

Na análise do levantamento efetuado, adotou-se o dedutivo. A dedução "é o processo pelo qual, com base em enunciados ou premissas, se chega a uma conclusão necessária, em virtude da correta aplicação de regras lógicas“ (MARCONI; LAKATOS, 2004).

De acordo com Cervo e Bervian (2005), a dedução é a relação lógica estabelecida entre proposições. Pela argumentação dedutiva o fato universal contém em si a explicação de outro igual, menos geral, ou seja, mostra as verdades particulares contidas nas universais (MARCONI; LAKATOS, 2004).

\section{RESULTADOS E DISCUSSÃO}

O trabalho de reflorestamento artificial da reserva legal, em todas as propriedades, já deveria ter sido iniciado, de acordo com o art. $2^{\circ}$., $\S 4^{\circ}$. da Lei Estadual 7.641/91, em 1992, inclusive, com a obrigação da regeneração artificial, à razão de 1/30 por ano. Dentro dessa perspectiva, os trabalhos de regeneração se iniciariam em 1992 e findariam no ano de 2021. Restam atualmente, portanto, 12 anos, contando com o de 2010, para que esse período se encerre.

Na tabela 1, apresenta-se a área total, a área a ser ocupada por Reserva Legal, de acordo com o percentual de 20\% disposto no Código Florestal Brasileiro, a área de mata natural, a área a reflorestar para compor o percentual de 20\% de Reserva Legal, a área de culturas e pastagens, a de reflorestamento, a de brejo/várzea e a área complementar, todas em hectares, das propriedades rurais por município componente 
da Regional de Botucatu da Secretaria de Agricultura do Estado de São Paulo, e para todo o estado, em levantamento realizado em 1995/1996.

Tabela 1 - Composição da ocupação do solo (ha) das propriedades rurais por município componente da Regional de Botucatu da Secretaria de Agricultura do Estado de São Paulo, em 1995/1996 e para todo o estado.

\begin{tabular}{|c|c|c|c|c|c|c|c|c|}
\hline \multirow[b]{2}{*}{ Município } & \multirow[b]{2}{*}{ Área total } & \multirow[b]{2}{*}{$\begin{array}{c}\text { Reserva } \\
\text { Legal }\end{array}$} & \multirow[b]{2}{*}{$\begin{array}{c}\text { Mata } \\
\text { natural }\end{array}$} & \multirow[b]{2}{*}{$\begin{array}{l}\text { A reflo- } \\
\text { restar }\end{array}$} & \multicolumn{3}{|c|}{ Reflo- } & \multirow[b]{2}{*}{$\begin{array}{l}\text { Comple- } \\
\text { mentar }\end{array}$} \\
\hline & & & & & $\begin{array}{l}\text { Culturas e } \\
\text { pastagens }\end{array}$ & $\begin{array}{c}\text { res- } \\
\text { tamento }\end{array}$ & $\begin{array}{l}\text { Inapro- } \\
\text { veitável }\end{array}$ & \\
\hline Anhembi & 59975,9 & 11995,2 & 6308,9 & 5686,3 & 49265,2 & 3520,3 & 237,6 & 643,9 \\
\hline Areiópolis & 9122,5 & 1824,5 & 97,4 & 1727,1 & 8687,7 & 34,7 & 69,8 & 232,9 \\
\hline Bofete & 60126,8 & 12025,4 & 7261,3 & 4764,1 & 36321,1 & 10146,3 & 2054,3 & 4343,8 \\
\hline Botucatu & 136663,5 & 27332,7 & 18379,7 & 8953,0 & 94049,8 & 19241,2 & 1897,2 & 3095,6 \\
\hline Conchas & 38532,3 & 7706,5 & 2525,0 & 5181,5 & 34624,1 & 628,4 & 587,7 & 167,1 \\
\hline Itatinga & 84529,2 & 16905,8 & 8436,9 & 8468,9 & 47524,6 & 24834,1 & 2572,4 & 1161,2 \\
\hline \multicolumn{9}{|l|}{ Laranjal } \\
\hline Pta. & 30926,0 & 6185,2 & 1065,4 & 5119,8 & 28421,1 & 308,0 & 86,0 & 1045,5 \\
\hline Pardinho & 19027,4 & 3805,5 & 1538,8 & 2266,7 & 15970,6 & 763,0 & 164,3 & 590,7 \\
\hline Pereiras & 20306,8 & 4061,4 & 813,5 & 3247,9 & 18886,9 & 127,8 & 80,5 & 398,1 \\
\hline Pratânia & 22826,3 & 4565,3 & 1582,4 & 2982,9 & 18219,2 & 2239,3 & 334,9 & 450,5 \\
\hline $\begin{array}{l}\text { São Ma- } \\
\text { nuel }\end{array}$ & 52556,3 & 10511,3 & 2889,0 & 7622,3 & 45389,7 & 1959,8 & 1500,6 & 817,2 \\
\hline Regional & 534593,0 & 106918,6 & 50898,3 & 56020,3 & 397360,0 & 63802,9 & 9585,3 & 12946,5 \\
\hline Estado & 19999485, & 3999896, & 1954150, & 2045746, & 16550782, & 812182, & 300797, & 381571, \\
\hline S.P. & 0 & 9 & 5 & 4 & 0 & 8 & 4 & 6 \\
\hline
\end{tabular}

Fonte: Projeto Lupa da Secretaria de Agricultura do Estado de São Paulo, 1995/1996.

Os dados da tabela 1 mostram que os municípios da região de Botucatu têm necessidade de reflorestar 56020,3 ha em toda a regional para compor, em nível macro, o percentual proposto para Reserva Legal. Em ordem decrescente de necessidade por município apresentam-se as necessidades de Botucatu, Itatinga, São Manuel, Anhembi, Conchas, Laranjal Paulista, Bofete, Pratânia, Pardinho e Areiópolis.

Na tabela 2, são apresentadas a área total (ha), a área a reflorestar (ha) para que se atinja os 20\% dispostos no código legal e a relação entre área de florestas e área total por município componente da Re- 
gional de Botucatu da Secretaria de Agricultura do Estado de São Paulo no levantamento realizado em 1995/1996.

Tabela 2 - Área total das propriedades, área a reflorestar e relação entre a área de mata natural e a área total, por município da Regional de Botucatu da Secretaria de Agricultura do Estado de São Paulo, em 1995/1996 e para todo o estado.

\begin{tabular}{lrcc}
\hline \multicolumn{1}{c}{ Município } & Área total & Área a reflorestar & $\begin{array}{c}\text { Relação área de mata natural e área } \\
\text { total }\end{array}$ \\
\hline Botucatu & 136663,5 & 8953,0 & 0,1345 \\
Bofete & 60126,8 & 4764,1 & 0,1208 \\
Anhembi & 59975,9 & 5686,3 & 0,1052 \\
Itatinga & 84529,2 & 8468,9 & 0,0998 \\
Pardinho & 19027,4 & 2266,7 & 0,0809 \\
Pratânia & 22826,3 & 2982,9 & 0,0693 \\
Conchas & 38532,3 & 5181,5 & 0,0655 \\
São Manuel & 52556,3 & 7622,3 & 0,0550 \\
Pereiras & 20306,8 & 3247,9 & 0,0401 \\
Laranjal Paulista & 30926,0 & 5119,8 & 0,0344 \\
Areiópolis & 9122,5 & 1727,1 & 0,0107 \\
\hline Regional & 534593,0 & 56020,3 & 0,0952 \\
\hline Estado S.P. & 19999485,0 & 2045746,4 & 0,0977 \\
\hline
\end{tabular}

Fonte: Projeto Lupa da Secretaria de Agricultura do Estado de São Paulo, 1995/1996.

A análise dos dados da tabela 2 mostra que Botucatu, Bofete e Anhembi já tinham à época de 1995/1996 respectivamente 13,45\%, 12,08\% e 10,52\% de área de mata natural em relação à área total das propriedades agrícolas, necessitando reflorestar 6,55\%, 7,92\% e 9,48\%. Em seguida apresentam-se Itatinga, Pardinho, Pratânia, Conchas, São Manuel, Pereiras, Laranjal Paulista e Areiópolis, com 1,07\%, necessitando reflorestar 18,93\% de sua área agrícola total. Deve ser lembrado mais uma vez que esta análise é macro regional e aproximada. Seria exata se os cálculos fossem efetuados por propriedade rural, algo que os dados do levantamento efetuado pela Secretaria de Agricultura impossibilitam.

No ano de 1996, quinto a partir de 1992, inclusive, estavam faltando 25 anos para o trabalho de composição da Reserva Legal. Com os dados da tabela 2 é possível calcular a quantidade de área que de- 
veria ser florestada à época, por ano, para que o objetivo de $20 \%$ da área total fosse atingido. A tabela 3 mostra esses dados.

A análise da tabela 3 mostra que o município de Botucatu é o que mais teria que reflorestar, 358,12 ha/ano, a partir de 1997, para que o percentual de 20\% de reserva legal fosse atingido em 2021, Itatinga ocupava a segunda posição. Em seguida vinham São Manuel, Anhembi, Conchas, Laranjal Paulista, Bofete, Pereiras, Pratânia, Pardinho e Areiópolis, com 69,08 ha/ano.

Tabela 3 - Área que deveria ser florestada, por ano, no período de 1997 a 2021 para compor a área de Reserva Legal, considerando o percentual de 20\%, por município e Regional de Botucatu da Secretaria de Agricultura do Estado de São Paulo.

\begin{tabular}{lcc}
\hline \multicolumn{1}{c}{ Município } & Área a reflorestar & Área a reflorestar por ano entre 1997 e 2021 \\
\hline Areiópolis & 1727,1 & 69,08 \\
Pardinho & 2266,7 & 90,67 \\
Pratânia & 2982,9 & 119,32 \\
Pereiras & 3247,9 & 129,92 \\
Bofete & 4764,1 & 190,56 \\
Laranjal Paulista & 5119,8 & 204,79 \\
Conchas & 5181,5 & 207,26 \\
Anhembi & 5686,3 & 227,45 \\
São Manuel & 7622,3 & 304,89 \\
Itatinga & 8468,9 & 338,76 \\
Botucatu & 8953,0 & 358,12 \\
\hline Regional Botuca- & & 2240,81 \\
tu & 56020,3 & \\
\hline
\end{tabular}

Fonte: Projeto Lupa da Secretaria de Agricultura do Estado de São Paulo, 1995/1996.

Na tabela 4, são apresentados o total das áreas das propriedades rurais, a área a ser ocupada por Reserva Legal, considerando-se o percentual de $20 \%$ da área total, a área de mata natural, a área a reflorestar para compor os $20 \%$ da área total, relativos à Reserva Legal, a área de culturas e pastagens, a de reflorestamento, a de brejo/várzea e a área complementar, em ha, por município da Regional de Botucatu da Secretaria de Agricultura do Estado de São Paulo, da Regional propriamente dita e de todo o estado de São Paulo, no levantamento efetuado em 2007/2008. 
A análise dos dados da tabela 4 mostra que os agricultores da regional Botucatu terão que reflorestar 38415,3 ha para atingir, no nível macro, a marca de 20\% de reserva legal, de acordo com o disposto no regulamento legal, sendo 6053,5 ha em São Manuel; 5427,0 ha em Laranjal Paulista; 5024,9 ha em Botucatu; 4826,6 ha em Conchas; 4416,0 ha em Anhembi; 3304,6 ha em Pereiras; 2580,5 ha em Pratânia; 1916,0 ha em Bofete; 1755,8 ha em Areiópolis; 1636,9 ha em Itatinga e finalmente 1473,5 ha em Pardinho.

Tabela 4 - Composição da ocupação do solo (ha) das propriedades rurais por município componente da Regional de Botucatu da Secretaria de Agricultura do Estado de São Paulo, em 2007/2008 e para todo o estado.

\begin{tabular}{|c|c|c|c|c|c|c|c|c|}
\hline Município & Área total & $\begin{array}{c}\text { Reserva } \\
\text { Legal }\end{array}$ & $\begin{array}{c}\text { Mata na- } \\
\text { tural }\end{array}$ & $\begin{array}{l}\text { A reflo- } \\
\text { restar }\end{array}$ & $\begin{array}{l}\text { Culturas e } \\
\text { pastagens }\end{array}$ & $\begin{array}{c}\text { Reflores- } \\
\text { tamento }\end{array}$ & $\begin{array}{c}\text { Inapro- } \\
\text { veitável }\end{array}$ & $\begin{array}{c}\text { Comple- } \\
\text { mentar }\end{array}$ \\
\hline Anhembi & 63763,2 & 12752,6 & 8336,6 & 4416,0 & 44513,9 & 9654,2 & 382,1 & 876,4 \\
\hline Areiópolis & 9735,7 & 1947,1 & 191,3 & 1755,8 & 9288,7 & 44,3 & 3,3 & 208,1 \\
\hline Bofete & 48874,4 & 9774,9 & 7858,9 & 1916,0 & 28897,4 & 10005,4 & 382,1 & 1730,6 \\
\hline Botucatu & 133534,9 & 26707,0 & 21682,1 & 5024,9 & 82546,6 & 22371,6 & 1068,2 & 5866,4 \\
\hline Conchas & 42182,3 & 8436,5 & 3609,9 & 4826,6 & 37219,7 & 718,5 & 219,4 & 414,8 \\
\hline Itatinga & 88112,6 & 17622,5 & 15985,6 & 1636,9 & 36137,0 & 33729,9 & 137,4 & 2122,7 \\
\hline Laranjal Pta. & 36751,3 & 7350,3 & 1923,3 & 5427,0 & 33118,1 & 311,6 & 182,2 & 1216,1 \\
\hline Pardinho & 21210,5 & 4242,1 & 2768,6 & 1473,5 & 17306,4 & 788,3 & 8,1 & 339,1 \\
\hline Pereiras & 20525 & 4105 & 800,4 & 3304,6 & 19031,7 & 209,5 & 14,3 & 469,1 \\
\hline Pratânia & 21749,2 & 4349,8 & 1769,3 & 2580,5 & 17205,9 & 1861,1 & 460,7 & 452,2 \\
\hline São Manuel & 52857,6 & 10571,5 & 4518,0 & 6053,5 & 44251,8 & 2687,5 & 155,6 & 1244,7 \\
\hline Regional & 539296,7 & 107859,3 & 69444,0 & 38415,3 & 369517,2 & 82381,9 & 3013,4 & 14940,2 \\
\hline Estado S.P. & 20504106,0 & 4100821,2 & 2432912,0 & 1667909,1 & 16258002,0 & 1023158,0 & 294754,0 & 495280,0 \\
\hline
\end{tabular}

Na tabela 5, são apresentadas a área total (ha), a área a reflorestar (ha) para atingir a marca de 20\% da área total e a relação entre a área de mata natural e a área total das propriedades rurais, por município componente da Regional de Botucatu da Secretaria de Agricultura do Estado de São Paulo no levantamento efetuado em 2007/2008. 
A análise dos dados da tabela 5 mostra que Itatinga, Botucatu e Bofete encontram-se bem próximos de atingir o mínimo de $20 \%$ da área agrícola coberta com mata natural, como disposto no Código Florestal Brasileiro. Os dados mostram, respectivamente, percentuais de 18,14\%, 16,24\% e 16,08\% de áreas de mata natural, em relação às áreas totais agrícolas para esses municípios, necessitando, portanto, reflorestar áreas equivalentes a 1,86\%, 3,76\% e 3,92\% ds suas áreas agrícolas. Os demais municípios apresentam necessidades de reflorestar para atingir esse mínimo um pouco maiores. Em ordem de necessidade aparecem Anhembi, com 13,07\%, ou seja, com necessidade de reflorestar 6,93\% de sua área total agrícola; Pardinho, com 13,05\%. Conchas, com 8,56\%; São Manuel, com 8,55\% e Pratânia, com 8,14\% apresentam situações críticas, ao passo que Laranjal Paulista, Pereiras e Areiópolis, respectivamente com 5,23\%, 3,90\% e 1,96\% situações bastante críticas, com necessidades de reposição, via reflorestamento, de 14,76\%, 16,10\% e 18,04\% de suas áreas totais agrícolas para que o percentual proposto no Código Florestal Brasileiro seja atendido, em nível macro.

Tabela 5 - Área total das propriedades, área a reflorestar e relação entre a área de mata natural e a área total, por município da Regional de Botucatu da Secretaria de Agricultura do Estado de São Paulo, em 2007/2008.

\begin{tabular}{lrcc}
\hline \multicolumn{1}{c}{ Município } & Área total & Área a reflorestar & Relação entre área de mata natural e área \\
\hline Itatinga & 88112,6 & 1636,9 & 0,1814 \\
Botucatu & 133534,9 & 5024,9 & 0,1624 \\
Bofete & 48874,4 & 1916,0 & 0,1608 \\
Anhembi & 63763,2 & 4416,0 & 0,1307 \\
Pardinho & 21210,5 & 1473,5 & 0,1305 \\
Conchas & 42182,3 & 4826,6 & 0,0856 \\
São Manuel & 52857,6 & 6053,5 & 0,0855 \\
Pratânia & 21749,2 & 2580,5 & 0,0814 \\
Laranjal Paulista & 36751,3 & 5427,0 & 0,0523 \\
Pereiras & 20525,0 & 3304,6 & 0,0390 \\
Areiópolis & 9735,7 & 1755,8 & 0,0196 \\
\hline Regional Botucatu & 539296,7 & 38415,3 & 0,1288 \\
\hline Estado de São Pau- & & & 0,1187 \\
lo & 20504106,0 & 1667909,1 &
\end{tabular}

Fonte: Calculados pelo autor. Dados provenientes do Projeto Lupa da Secretaria de Agricultura do Estado de São Paulo, 2007/2008 
No ano de 2008, décimo sétimo a partir de 1992, inclusive, estavam faltando 13 anos para o prazo de composição da Reserva Legal. Com os dados da tabela 5 é possível calcular a quantidade de área que deveria ser florestada por ano, a partir de 2009 inclusive, para que o objetivo seja atingido. Com a finalidade de verificar possíveis alterações no ritmo de composição de florestas nos dois períodos levantados pela Secretaria de Agricultura do Estado de São Paulo, são apresentadas as necessidades de reflorestar, por ano, nos períodos de 1997 a 2021 e entre 2009 e 2021, e a relação entre elas. A tabela 6 mostra esses dados e relações.

A análise dos dados da tabela 6 mostra necessidades de compor a reserva legal, via reflorestamento, com taxas variando de 113,35 ha/ano, em Pardinho, até 465,65 ha/ano em São Manuel, para que seja cumprido, em nível macro, o percentual proposto pelo Código Florestal Brasileiro para composição da Reserva Legal.

Tabela 6 - Área a reflorestar (ha), área a reflorestar por ano, no período de 2009 a 2021 para compor a área de Reserva Legal (ha), área a reflorestar, por ano (ha/ano), no período de 1997 a 2021 e relação entre essas áreas, por município e Regional da Secretaria de Agricultura do Estado de São Paulo.

\begin{tabular}{lcccc}
\hline \multicolumn{1}{c}{ Município } & $\begin{array}{c}\text { Área a } \\
\text { reflorestar }\end{array}$ & $\begin{array}{c}\text { Área a reflorestar } \\
\text { por ano no período } \\
\text { de 2009 a 2021 }\end{array}$ & $\begin{array}{c}\text { Área a reflorestar } \\
\text { por ano no período } \\
\text { de 1997 e 2021 }\end{array}$ & $\begin{array}{c}\text { Relação entre áreas a re- } \\
\text { florestar entre 2009/2021 e } \\
1997 / 2021\end{array}$ \\
\hline Itatinga & 1636,9 & 125,92 & 338,76 & 0,372 \\
Bofete & 1916,0 & 147,38 & 190,56 & 0,773 \\
Botucatu & 5024,9 & 386,53 & 358,12 & 1,079 \\
Pardinho & 1473,5 & 113,35 & 90,67 & 1,250 \\
Anhembi & 4416,0 & 339,69 & 227,45 & 1,493 \\
São Manuel & 6053,5 & 465,65 & 304,89 & 1,527 \\
Pratânia & 2580,5 & 198,50 & 119,32 & 1,664 \\
Conchas & 4826,6 & 371,28 & 207,26 & 1,791 \\
Areiópolis & 1755,8 & 135,06 & 69,08 & 1,955 \\
Pereiras & 3304,6 & 254,20 & 129,92 & 1,957 \\
Laranjal Paulista & 5427,0 & 417,46 & 204,79 & 2,038 \\
\hline Regional Botucatu & 38415,3 & 2955,02 & 2240,81 & 1,319 \\
\hline
\end{tabular}

Fonte: Projeto Lupa da Secretaria de Agricultura do Estado de São Paulo, 1995/1996.

Mostra também que Itatinga e Bofete apresentam necessidade de implantar área florestal no período de 2009 a 2021 (projetado com o levantamento efetuado em 2008) numa proporção menor do que 
apresentava no período de 1997 e 2021 (projetada com o levantamento efetuado em 1996). Para atingir a meta de $20 \%$ da área total rural com florestas, Itatinga apresentava uma taxa de 338,76 ha/ano para formação de área correspondente ao proposto para Reserva Legal no ano de 1996, passando para atuais 125,92 ha/ano no ano de 2009. Bofete passou de uma necessidade de 190,56 ha/ano em 1996 para 147,38 ha/ano em 2009.

Todos os outros nove municípios da regional aumentaram as taxas de necessidade de formação de florestas por ano, entre 2009 e 2021, quando comparadas às necessidades que detinham em 1996. Areiópolis, Pereiras e Conchas apresentam as maiores variações nas taxas. Areiópolis passou de uma taxa de 69,08 ha/ano em 1996 para 135,06 ha/ano em 2009. Pereiras de 129,92 ha/ano em 1996 para 254,20 ha/ano em 2009. Conchas apresenta o pior resultado, passando de 204,79 ha/ano em 1996 para mais que o dobro em 2009, ou seja 417,46 ha/ano.

Com os dados da tabela 6 e da tabela 3 foi possível calcular diferenças entre áreas totais rurais e áreas florestadas entre os levantamentos efetuados em 1995/1996 e 2007/2008, isto é, num período de 12 anos. A partir desse dados foi possível calcular a taxa de florestamento efetivo ocorrido nesse período e compensá-la pela taxa de crescimento efetivo da área total. Com esses dados é composta a tabela 7, onde são apresentadas a área a reflorestar (ha/ano), no período de 2009 e 2021 para compor o percentual proposto para área de Reserva Legal, a área efetivamente regenerada de mata natural entre 1996 e 2008 (ha), a taxa de regeneração efetiva entre 1996 e 2008 (ha/ano), a relação entre a área a reflorestar por ano entre 2009 e 2021 e a regenerada entre 1996 e 2008, o crescimento da área total das propriedades rurais e a compensação da relação pelo crescimento da área total, por município e Regional da Secretaria de Agricultura do Estado de São Paulo. 
Tabela 7 - Área a reflorestar no período de 2009 e 2021, área efetivamente regenerada de mata natural entre 1996 e 2008, taxa de regeneração efetiva entre 1996 e 2008, relação entre a área a reflorestar por ano entre 2009 e 2021 e a regenerada entre 1996 e 2008, crescimento da área total das propriedades rurais e compensação da relação pelo crescimento da área total, por município e Regional da Secretaria de Agricultura do Estado de São Paulo.

\begin{tabular}{|c|c|c|c|c|c|c|}
\hline Município & $\begin{array}{l}\text { A reflo- } \\
\text { restar por } \\
\text { ano entre } \\
2009 \text { e } \\
2021 \text { (A) }\end{array}$ & $\begin{array}{c}\text { Área de } \\
\text { mata natu- } \\
\text { ral regene- } \\
\text { rada entre } \\
1996 \text { d } \\
2008\end{array}$ & $\begin{array}{c}\text { Taxa de } \\
\text { regeneração } \\
\text { da mata na- } \\
\text { tural entre } \\
1996 \text { e } 2008 \\
\text { (B) }\end{array}$ & A / B & $\begin{array}{l}\text { Crescimento } \\
\text { da área total }\end{array}$ & $\begin{array}{l}\text { Compensação } \\
\text { de A / B pelo } \\
\text { crescimento } \\
\text { da área total }\end{array}$ \\
\hline Pereiras & 254,20 & $-13,10$ & $-1,09$ & - & 1,0107 & - \\
\hline Itatinga & 125,92 & 7548,70 & 629,06 & 0,2002 & 1,0424 & 0,1920 \\
\hline Pardinho & 113,35 & 1229,80 & 102,48 & 1,1060 & 1,1147 & 0,9922 \\
\hline Botucatu & 386,53 & 3302,40 & 275,20 & 1,4045 & 0,9771 & 1,4375 \\
\hline Anhembi & 339,69 & 2027,70 & 168,98 & 2,0103 & 1,0631 & 1,8910 \\
\hline São Manuel & 465,65 & 1629,00 & 135,75 & 3,4302 & 1,0057 & 3,4108 \\
\hline Bofete & 147,38 & 597,60 & 49,80 & 2,9595 & 0,8128 & 3,6412 \\
\hline Conchas & 371,28 & 1084,90 & 90,41 & 4,1067 & 1,0947 & 3,7514 \\
\hline Laranjal Paulista & 417,46 & 857,90 & 71,49 & 5,8393 & 1,1884 & 4,9136 \\
\hline Pratânia & 198,50 & 186,90 & 15,58 & 12,7448 & 0,9528 & 13,3761 \\
\hline Areiópolis & 135,06 & 93,90 & 7,83 & 17,2603 & 1,0672 & 16,1734 \\
\hline $\begin{array}{l}\text { Regional Botuca- } \\
\text { tu }\end{array}$ & 2955,02 & 18545,70 & 1545,48 & 1,9120 & 1,0088 & 1,8954 \\
\hline
\end{tabular}

Fonte: Projeto Lupa da Secretaria de Agricultura do Estado de São Paulo, 1995/1996 e 2007/2008

A análise dos dados da tabela 7 mostra situação bastante preocupante no município de Pereiras, onde houve decréscimo da área de mata natural no período considerado. Em seguida apresenta-se a situação de Areiópolis que deverá reflorestar áreas para composição da Reserva Legal, em nível macro, numa taxa 16,17 vezes maior que a regeneração de sua mata natural no período de 1996 a 2008. Pratânia vem logo a seguir com taxa 13,38 vezes. A situação de Itatinga é muito confortável, também o sendo, porém em menor magnitude, a de Pardinho, pois o reflorestamento nesses municípios deverá ocorrer com taxa mais baixa do que a taxa de regeneração efetiva da mata natural entre 1996 e 2008. 
Na tabela 8 apresentam-se os índices de Gini, utilizados para avaliar a concentração de área por proprietário (ou propriedade), calculados para cada um dos municípios da Regional de Botucatu para os anos de 1995/1996 e 2007/2008.

A análise das informações contidas na tabela 8 mostra que nos diversos municípios da região ocorreram fenômenos tanto de concentração, quanto de descontração durante o período de 1996/1996 a 2007/2008.

Tabela 8 - Índice de Gini para a concentração de área por proprietário, calculado por município, Regional da Secretaria da Agricultura do Estado de São Paulo e todo o estado, para os anos de 1995/1996 e $2007 / 2008$

\begin{tabular}{lcc}
\hline \multicolumn{1}{c}{ Município } & Índice de Gini $-1995 / 1996$ & Índice de Gini - 2007/2008 \\
\hline Laranjal Paulista & 0,5869 & 0,5929 \\
Pereiras & 0,6063 & 0,6033 \\
Conchas & 0,6110 & 0,6204 \\
Pardinho & 0,6049 & 0,6830 \\
Anhembi & 0,7206 & 0,6851 \\
Pratânia & 0,6591 & 0,7102 \\
Bofete & 0,7358 & 0,7152 \\
Itatinga & 0,6820 & 0,7306 \\
Areiópolis & 0,7448 & 0,7740 \\
São Manuel & 0,7601 & 0,7813 \\
Botucatu & 0,7694 & 0,7829 \\
\hline Regional Botucatu & 0,7496 & 0,7564 \\
\hline Estado & 0,7292 & 0,7305 \\
\hline
\end{tabular}

Fonte: Calculados pelo autor. Dados provenientes do Projeto Lupa da Secretaria de Agricultura do Estado de São Paulo, 1995/1996 e 2007/2008

Houve desconcentração de área por propriedade em Anhembi, Bofete e Pereiras. Por outro lado houve concentração de área por propriedade nos municípios de Areiópolis, Botucatu, Conchas, Itatinga, Laranjal Paulista, Pardinho, Pratânia e São Manuel. Houve, em nível de estado, uma tendência para concentração: as propriedades ficaram levemente menos uniformes nas diversas propriedades. Na região de Botucatu esse comportamento manteve-se praticamente igual. Botucatu detém a maior concentração. Pra- 
ticamente a mesma situação encontra-se no município de São Manuel. Durante o período de análise de 1995/1996 a 2007/2008 esses índices tiveram leves aumentos mostrando que as áreas por propriedade tornaram-se levemente menos uniformes, fator importante para a questão de políticas públicas.

Quando as propriedades têm áreas mais uniformes os esforços individuais dos proprietários são mais parecidos e o reflorestamento pode ser efetuado com uma divisão de tarefa mais uniforme. Há uma tendência de todos fazerem desembolsos semelhantes. O florestamento é feito com mais justiça e participação de todos. Essa situação ocorre em Laranjal Paulista. Apesar do índice de concentração ser considerado de médio a forte, as propriedades são mais uniformes que aquelas de Botucatu. Em Botucatu teoricamente alguns proprietários arcariam com maiores despesas que outros se fosse necessária a efetivação da área recomendada de $20 \%$ contida no texto legal.

Na tabela 9, apresentam-se a população rural, o consumo per capita rural (US\$/habitante) no ano de 2008, o consumo total rural (US\$) no ano de 2008, a área total rural (ha) e o índice 1, dado pela relação entre o consumo rural total em US\$ em 2008 e a área a reflorestar no período de 2009 a 2021 em ha, por município e Regional da Secretaria de Agricultura do Estado de São Paulo. O índice 1 foi criado para aferir sobre a facilidade ou não da implantação dos $20 \%$ referentes à Reserva Legal, em nível macro, até o ano de 2021, por existir relação direta na economia entre a renda e o consumo. Muitas vezes o uso de área para composição da Reserva Legal é feito em detrimento de áreas de culturas, pastagens, reflorestamento comerciais ou outros fins, o que representa queda de receita. 
Tabela 9 - População rural, consumo per capita rural no ano de 2008, consumo rural total no ano de 2008 (US\$), área total rural (ha) e índice 1, dado pela relação entre o consumo rural total em 2008 e a área a reflorestar no período de 2009 a 2021, por município e Regional da Secretaria de Agricultura do Estado de São Paulo.

\begin{tabular}{lccccc}
\hline \multicolumn{1}{c}{ Município } & $\begin{array}{c}\text { População } \\
\text { rural }\end{array}$ & $\begin{array}{c}\text { Consumo per } \\
\text { capita }\end{array}$ & $\begin{array}{c}\text { Consumo } \\
\text { rural total }\end{array}$ & $\begin{array}{c}\text { Área a reflores- } \\
\text { tar }\end{array}$ & Índice 1 \\
\hline Bofete & 2548 & 2581,49 & 6577636,5 & 1916,0 & 3433 \\
Botucatu & 4740 & 3074,21 & 14571755,0 & 5024,9 & 2900 \\
Pratânia & 1131 & 6050,22 & 6842798,8 & 2580,5 & 2652 \\
Itatinga & 1920 & 1934,07 & 3713414,4 & 1636,9 & 2269 \\
Conchas & 3577 & 2914,56 & 10425381,0 & 4826,6 & 2160 \\
Pereiras & 2619 & 2574,65 & 6743008,4 & 3304,6 & 2040 \\
Pardinho & 1201 & 2176,04 & 2613424,0 & 1473,5 & 1774 \\
Laranjal Paulis- & & & & & \\
ta & 2118 & 2579,45 & 5463275,1 & 5427,0 & 1007 \\
Anhembi & 1650 & 2371,07 & 3912265,5 & 4416,0 & 886 \\
Areiópolis & 1050 & 1469,12 & 1542576,0 & 1755,8 & 879 \\
São Manuel & 1669 & 2360,47 & 3939624,4 & 6053,5 & 651 \\
\hline Regional & 24223 & - & 66345160,0 & 38415,3 & 1727 \\
\hline
\end{tabular}

Fonte: Calculados pelo autor. Dados provenientes dos Índices Target do ano de 2008 e do Projeto Lupa da Secretaria de Agricultura do Estado de São Paulo, 1995/1996 e 2007/2008

A análise do índice 1 mostra que Laranjal Paulista, Anhembi, Areiópolis e São Manuel encontram-se abaixo da média regional, portanto terão maior dificuldade na implantação do reflorestamento que Pereiras e Pardinho que encontram-se com índices levemente superiores à média. O índice de São Manuel mostra que os recursos serão quatro vezes mais escassos que os de Pratânia.

A implantação de áreas de florestas se daria, caso fosse efetuada, em detrimento das áreas de culturas e pastagens. Assim, construiu-se a tabela 10 que contém a área a reflorestar (ha) no período de 2009 a 2021 para compor a área de Reserva Legal em nível macro, a área de culturas e pastagens (ha) no ano de 2008 e a proporção que a área a reflorestar representaria em relação à área de culturas e pastagens.

Os municípios da região de Botucatu, em nível macro, deverão substituir 10,40\% das áreas de culturas e pastagens por florestas. Os municípios com maiores dificuldades de substituição são os de Arei- 
ópolis, Pereiras, Laranjal Paulista, Pratânia, São Manuel e Conchas. Em situação pouco melhor encontram-se Anhembi, Pardinho, Bofete, Botucatu e Itatinga.

Tabela 10 - Área a reflorestar no período de 2009 e 2021 para compor a área de Reserva Legal, área de culturas e pastagens em 2008, proporção de área de culturas e pastagens a ser substituída por floresta, por município e Regional da Secretaria de Agricultura do Estado de São Paulo.

\begin{tabular}{lccc}
\hline \multicolumn{1}{c}{ Município } & Área a reflorestar & $\begin{array}{c}\text { Área de culturas e } \\
\text { pastagens }\end{array}$ & $\begin{array}{c}\text { Proporção de área de culturas e pas- } \\
\text { tagens a ser substituída por floresta }\end{array}$ \\
\hline Itatinga & 1636,9 & 36137,0 & 0,0453 \\
Botucatu & 5024,9 & 82546,6 & 0,0609 \\
Bofete & 1916,0 & 28897,4 & 0,0663 \\
Pardinho & 1473,5 & 17306,4 & 0,0851 \\
Anhembi & 4416,0 & 44513,9 & 0,0992 \\
Conchas & 4826,6 & 37219,7 & 0,1297 \\
São Manuel & 6053,5 & 44251,8 & 0,1368 \\
Pratânia & 2580,5 & 17205,9 & 0,1500 \\
Laranjal Paulista & 5427,0 & 33118,1 & 0,1639 \\
Pereiras & 3304,6 & 19031,7 & 0,1736 \\
Areiópolis & 1755,8 & 9288,7 & 0,1890 \\
\hline Regional Botucatu & 38415,3 & 369517,2 & 0,1040 \\
\hline Fonte: Calculados pelo autor. Dados provenientes do Projeto Lupa da Secretaria de Agricultura do Estado de São \\
Paulo, 2007/2008
\end{tabular}

Utilizando as variáveis V1 - Relação entre área de mata natural e área total; V2 - Relação entre áreas a reflorestar entre 2009/2021 e 1997/2021; V3 - Relação entre área a reflorestar por ano entre 2009 e 2021 e taxa de regeneração efetiva da mata natural entre 1996 e 2008, compensada pelo crescimento da área total; V4 - Índice de Gini calculado para 2007/2008; V5 - Índice 1 (consumo total rural anual dividido pela área em hectare a reflorestar no município no período de 2009 a 2021 para que sejam cumpridos os $20 \%$ contidos no código legal) e V6 - proporção de área de culturas a ser substituída por floresta no município, tendo por base a área de culturas levantada em 2008, construiu-se a tabela 11. 
Tabela 11 - Valores das variáveis V1, V2, V3, V4, V5 e V6, por município da Regional de Botucatu da Secretaria de Agricultura do Estado de São Paulo.

\begin{tabular}{lccrcrc}
\hline \multicolumn{1}{c}{ Municípios } & V1 & V2 & V3 & V4 & V5 & V6 \\
\hline Anhembi & 0,1307 & 0,708 & 1,8910 & 0,6851 & 886 & 0,0992 \\
Areiópolis & 0,0196 & 1,851 & 16,1734 & 0,7740 & 879 & 0,1890 \\
Bofete & 0,1608 & 0,306 & 3,6412 & 0,7152 & 3433 & 0,0663 \\
Botucatu & 0,1624 & 0,354 & 1,4375 & 0,7829 & 2900 & 0,0609 \\
Conchas & 0,0856 & 1,204 & 3,7514 & 0,6204 & 2160 & 0,1297 \\
Itatinga & 0,1814 & 0,186 & 0,1920 & 0,7306 & 2269 & 0,0453 \\
Laranjal Paulis- & & & & 0,5929 & & 0,1639 \\
ta & 0,0523 & 1,687 & 4,9136 & & 1007 & \\
Pardinho & 0,1305 & 0,745 & 0,9922 & 0,6830 & 1774 & 0,0851 \\
Pereiras & 0,0390 & 1,565 & infinito & 0,6033 & 2040 & 0,1736 \\
Pratânia & 0,0814 & 1,087 & 13,3761 & 0,7102 & 2652 & 0,1500 \\
São Manuel & 0,0855 & 1,108 & 3,4108 & 0,7813 & 651 & 0,1368 \\
\hline
\end{tabular}

Classificando os valores de V1 a V5 em postos variando de 1 até 11, onde 1 significa a situação mais favorável para a variável e 11 a menos favorável e finalmente calculando a soma desses postos, por município, é possível construir a tabela 12 que retrata a dificuldade ou facilidade que cada município encontrará para a composição dos $20 \%$ da área total agrícola em florestas, de acordo com o disposto no Código Florestal Brasileiro.

O município de Areiópolis, que apresenta as piores classificações para as variáveis V1, V2 e V6; as segundas piores classificação para V3 e V5 e a terceira pior para V4, encontrará maior dificuldade para implantação dos 20\% de florestas, que os municípios de Pereiras, São Manuel, Laranjal Paulista, Pratânia, Conchas e Anhembi que, pelas classificações das variáveis utilizadas, refletem dificuldades médias.

Pardinho, Botucatu, Bofete e Itatinga enfrentarão as menores dificuldades, por apresentarem, com exceção da variável V4 (índice de Gini calculado para 2007/2008) em Botucatu, os menores valores para a classificação das variáveis utilizadas. 
Tabela 12 - Postos das variáveis V1, V2, V3, V4, V5 e V6, por município da Regional de Botucatu da Secretaria de Agricultura do Estado de São Paulo.

\begin{tabular}{lrrrrrrr}
\hline \multicolumn{1}{c}{ Municípios } & V1 & V2 & V3 & V4 & V5 & V6 & Total \\
\hline Itatinga & 1 & 1 & 1 & 8 & 4 & 1 & 16 \\
Bofete & 3 & 2 & 6 & 7 & 1 & 3 & 22 \\
Botucatu & 2 & 3 & 3 & 11 & 2 & 2 & 23 \\
Pardinho & 5 & 5 & 2 & 4 & 7 & 4 & 27 \\
Anhembi & 4 & 4 & 4 & 5 & 9 & 5 & 31 \\
Conchas & 6 & 8 & 7 & 3 & 5 & 6 & 35 \\
Pratânia & 8 & 6 & 9 & 6 & 3 & 8 & 40 \\
Laranjal Paulista & 9 & 10 & 8 & 1 & 8 & 9 & 45 \\
São Manuel & 7 & 7 & 5 & 10 & 11 & 7 & 47 \\
Pereiras & 10 & 9 & 11 & 2 & 6 & 10 & 48 \\
Areiópolis & 11 & 11 & 10 & 9 & 10 & 11 & 62 \\
\hline
\end{tabular}

\section{CONCLUSÕES}

Os municípios de Anhembi, Areiópolis, Bofete, Botucatu, Conchas, Laranjal Paulista, Pardinho, Pratânia e São Manuel terão de aumentar a velocidade de implantação de área florestada, quando comparada à velocidade de regeneração efetiva de suas áreas de mata natural, para, numa condição macro, atingir os $20 \%$ da área total com florestas. As maiores velocidades deverão ser implementadas pelos municípios de Areiópolis e Pratânia.

Os municípios de Itatinga e Pardinho terão que empregar taxas de implantação menores que a verificada para a taxa de regeneração da área de mata natural entre 1996 e 2008. O município de Pereiras apresentou no mesmo período leve involução na área de mata natural.

Levando em conta as variáveis estudadas e seus postos, o município de Areiópolis terá maior dificuldade para implantação dos $20 \%$ de florestas relativos à Reserva Legal, em nível macro, até o ano de 2021, quando termina o prazo disposto no Código Legal. Considerando-se as mesmas variáveis, os municípios de Anhembi, Conchas, Laranjal Paulista, Pereiras, Pratânia e São Manuel, terão dificuldades médias, enquanto que Bofete, Botucatu, Itatinga e Pardinho encontrarão as menores dificuldades. 


\section{REFERÊNCIAS}

CERVO, A. L.; BERVIAN, P. A. Metodologia científica. 5. ed. São Paulo: Pearson, 2005. 242 p.

HOFFMANN, R. Estatística para economistas. São Paulo: Pioneira, 1980. 379 p.

HOFFMANN, R. A desigualdade da distribuição da posse de terra e o desenvolvimento humano. In: CONGRESSO BRASILEIRO DE ECONOMIA E SOCIOLOGIA RURAL, 39., 2001, Recife (PE). Anais... Recife: SOBER, 2001,1 CD-ROM.

HOFFMANN, R. A curva de Lorenz e o índice de Gini. In: HOFFMANN, R. Distribuição de renda. Medidas de desigualdade e pobreza. São Paulo: Edusp, 1998. p. 33-97.

MARCONI, M. A.; LAKATOS, E. M. Metodologia científica. 4. ed. São Paulo: Atlas, 2004. 305 p.

OLIVETTE, M. P. A.; CAMARGO, F. P. Concentração fundiária no estado de São Paulo, 1996-2008. Informações econômicas, São Paulo, v. 39, n. 6, jun. 2009. p. 68-76.

SÃO PAULO (Estado). Levantamento Censitário das Unidades de Produção Agrícola do Estado de São Paulo. LUPA 1995/1996. São Paulo: IEA/CATI/SAA, 1997. Disponível em:

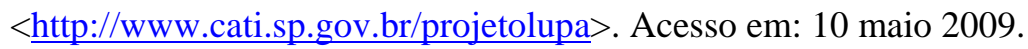

SÃO PAULO (Estado). Projeto LUPA 2007/2008. Censo Agropecuário do Estado de São Paulo. CATI/IEA/SAA, 2009. Disponível em: <http://www.cati.sp.gov.br/projetolupa>. Acesso em: 9 set 2009.

TARGET DO BRASIL. Índices Target ano de 2008. Disponível em:

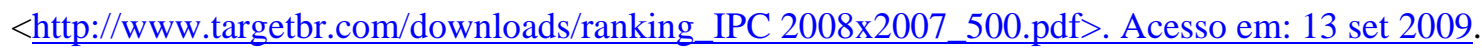

